\title{
Energy Efficiency in Building: Case of Buildings at the University of Ibadan, Nigeria
}

\author{
K. M. Odunfa ${ }^{1}$, T. O. Ojo ${ }^{1}$, V. O. Odunfa ${ }^{2}$, O. S. Ohunakin ${ }^{3}$ \\ ${ }^{1}$ Department of Mechanical Engineering, University of Ibadan, Ibadan, Nigeria \\ ${ }^{2}$ Department of Estate Management, The Polytechnic Ibadan, Ibadan, Nigeria \\ ${ }^{3}$ Department of Mechanical Engineering, Covenant University, Ota, Nigeria \\ Email: *m.odunfa@mail.ui.edu.ng
}

Received 20 February 2015; accepted 6 March 2015; published 12 March 2015

Copyright (C) 2015 by authors and Scientific Research Publishing Inc.

This work is licensed under the Creative Commons Attribution International License (CC BY).

http://creativecommons.org/licenses/by/4.0/

(c) (i) Open Access

\begin{abstract}
Nigeria today faces serious challenge in providing adequate energy to meet the needs of her citizenry. Efforts are currently geared towards generation of more energy to ease the problem. While these efforts are commendable, it is equally desirable to explore ways to minimize consumption of generated energy. The objective of this work is to investigate the effect of building orientation on energy demand in buildings. This paper considered the use of standard design considerations, fundamental cooling load equations and the guidelines stipulated by the American Society of Heating, Cooling and Air conditioning Engineers (ASHRAE). The study takes the designs of three buildings within the University of Ibadan, Nigeria into consideration with the view to harness the energy saving potentials through building orientation and selection of efficient cooling equipment. The results obtained were $155.34,224.75,86.35 \mathrm{~kW}$ and $163.60,232.04$ and $90.64 \mathrm{~kW}$ for the three lecture envelopes including the Faculty of Science, CBN and the Department of Chemistry lecture theatres using the North-South and East-West building orientations respectively. Increase in energy demand of 7.96, 7.29 and $4.29 \mathrm{~kW}$ was thus obtained with the East-West building orientation over North-South. Energy efficiency is thus guaranteed with North-South building orientation.
\end{abstract}

\section{Keywords}

Energy Efficiency, Orientation, Cooling Load, Heating Ventilation and Air-Conditioning

\footnotetext{
${ }^{*}$ Corresponding author.
}

How to cite this paper: Odunfa, K.M., Ojo, T.O., Odunfa, V.O. and Ohunakin, O.S. (2015) Energy Efficiency in Building: Case of Buildings at the University of Ibadan, Nigeria. Journal of Building Construction and Planning Research, 3, 18-26. 


\section{Introduction}

Energy efficiency requirements in buildings tend to focus upon improved envelope (walls, floors, roofs, doors, windows) design and efficient mechanical equipment performance such as heating, cooling, domestic hot water etc. This concept plays a large role in energy efficiency standards through the specification of minimum efficiencies for many items of mechanical and electrical equipment for buildings. Buildings account for a large part of the annual energy consumption in modern societies; within the European Union (EU), energy use by built environ-ment is more than $40 \%$ of the total energy consumption [1]. In building, envelope is one of the most important components with respect to total heat gain of the whole building and overall heat transfer coefficient that determines heat gain through the building envelope. In addition, orientation also plays a critical role on the thermal comfort of occupants. Studies of thermal comfort show that the way indoor thermal environment is evaluated and thus depends on the relationship between people, climate and building; these can vary over time [2]. Energy efficient design through proper selection of appropriate orientation, has direct impact on the performances of the building envelope and thus minimize solar intensity of the Sun's radiation. The total number of people living in urban areas around the world almost doubled between 1970 and 1995; urbanisation thus brings about population increase which ultimately leads to increased energy use in buildings. With rapid economic growth that calls for rising enery demand, there is a growing desire for better indoor built environment, particularly for comfort cooling during the dry season (a hot season that is peculiar to Nigeria due to her location on the tropic). Heating, ventilation and air conditioning (HVAC) systems which brought about building comfort during this hot season, were estimated to account for some $65 \%$ of the total energy use in the building sector [3] [4]. Since larger proportion of energy are being consumed in buildings, a way to alleviate the ever growing energy demand is to have more energy efficient building designs and proper building energy conservation programmes [5].

Several work had been done on building energy efficiency. Balcomb and McFarland [6], investigated the energy performance of several passive solar wall systems and various thermal mass storage materials; all systems were tested in field conditions inside a $2.6 \times 1.9 \times 2.9 \mathrm{~m}(100 \times 80 \times 120 \mathrm{in})$ insulated lightweight containers. In the work of Matsuo et al., [7], a simplified method to estimate annual air-conditioning load referred to as the Expanded Degree-Day Method where solar radiation and long wave radiation were considered as part of the expanded degree-days, was developed. A three-year (1982 to 1984) study to find the potential for energy savings in buildings (an occupied $372 \mathrm{~m}^{2}$ dormitory in Oak Ridge, Tennessee) using massive envelope materials was demostrated in the work of Christian [8]; whole building energy simulations were performed by employing DOE2.1B computer model calibrated using experimental data collected and analyzed during the testing period of the dormitory. Massive building envelope components in the computer model were replaced by wood-frame components whereas predicted energy demands with the wood frame were later compared with energy required in the massive building components; comparisons showed a potential $10 \%$ and $13 \%$ savings in cooling and heating energy respectively. Furthermore, analysis of a study on building energy consumption in Hong Kong, Singapore and Saudi Arabia in the work of Lam and Li [9]; Cheok [10]; Al-Najem [11], show that building envelope design accounts for $36 \%, 25 \%$ and $43 \%$ of the peak cooling load respectively. Lam et al., [5] reported a study that investigated the impact of façade's surfaces orientation on the intensity of the direct and indirect solar radiation; findings from this study showed that the north has the lowest solar intensity which varies from $43.6 \mathrm{~W} / \mathrm{m}^{2}$ in October to $65.5 \mathrm{~W} / \mathrm{m}^{2}$ in July. La Roche and Liggett [12], expressed in their work that climate responsive design of buildings is important not only because of the comfort and energy saving implications for its users, but also because it helps preserve valuable resources on our planet. Also, a survey on workplace occupant satisfaction in 16 office buildings in Germany revealed that occupants' control of the indoor climate, and moreover the perceived effect of their intervention strongly influence their satisfaction with thermal indoor conditions [13]. However, despite the enomous work carried out on building energy efficiency in the developed world, no research work currently exist in the subject area in Africa, the developing and the Least Developed economies, inspite of the looming energy crises in the respective locations. This study thus focused on the influence of various building orientations and natural ventilation on indoor envelope/environmental performance of three lecture theatres at the University of Ibadan, Nigeria.

\section{Design Procedure}

Nigeria is a country in the tropical region and lies approximately between $4^{\circ}$ and $13^{\circ}$ north of the equator with a landmass of $9.24 \times 105 \mathrm{~km}^{2}$. The country enjoys an average daily sunshine duration of 6.25 hours that range 
between approximately 3.5 hours at the coastal areas and 9.0 hours at the far northern boundary [14] [15]. Nigeria is characterized with a tropical climate with two seasons viz: dry season from October to March and rainy season from April to October. The climate is hot and dry in the north while it is hot and wet in the south [16]. Three lecture theatres including: 1) Faculty of Science Lecture Theatre; 2) CBN Lecture Theatre and 3) Department of Chemistry Lecture Theatre of the University of Ibadan in south-west, Nigeria, were selected as case studies (refer to Figures 1-3). The respective capacities of the theatres are 450, 1000 and 250. The theatres function mainly as students' lecture halls with no effect of outdoor shadings (trees etc.).

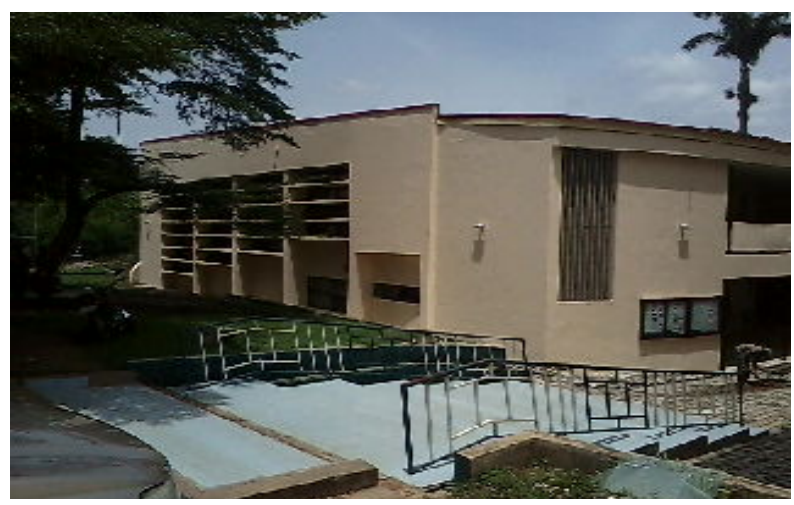

Figure 1. Faculty of Science Lecture Theatre, University of Ibadan, Nigeria.

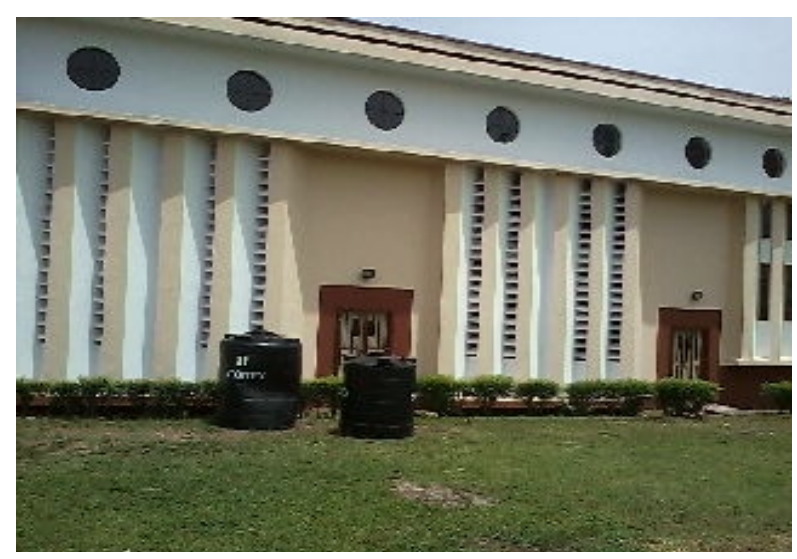

Figure 2. CBN Lecture Theatre, University of Ibadan, Nigeria.

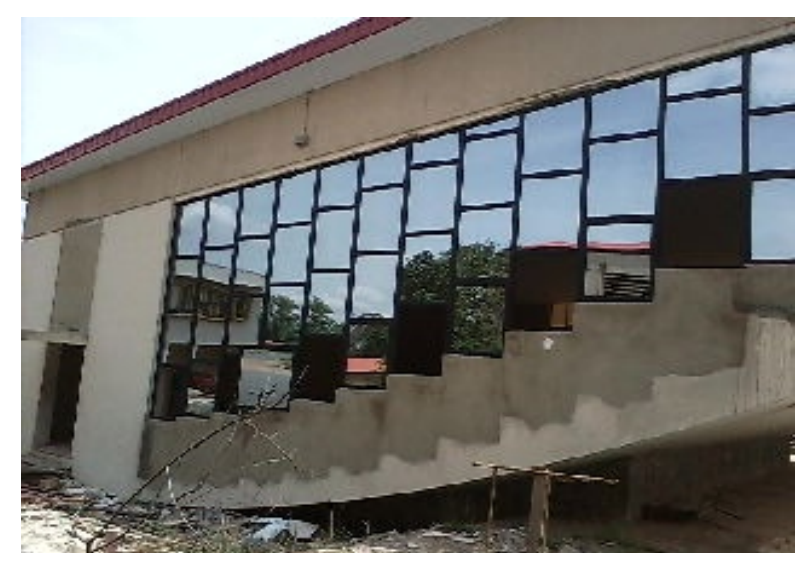

Figure 3. Chemistry Lecture Theatre, University of Ibadan, Nigeria. 
Cooling Load Temperature Difference/Cooling Load Factor (CLTD/CLF) method was adopted in this work in line with the American Society of Heating, Refrigeration and Air-Conditioning Engineers (ASHRAE) fundamental handbook guideline for cooling load estimation; the technique has been successfully used in buildings around the world. Furthermore, the accuracy of cooling load calculations in practice depends primarily on the availability of accurate information and the design engineer's judgment in the assumptions made in interpreting the available data [17].

\section{Cooling Loads}

\subsection{External Cooling Loads}

The total cooling load on a building consists of external as well as internal loads. The external loads consist of heat transfer by conduction through the building walls, roof, floor, doors etc. together with heat transfer by radiation through fenestration such as windows and skylights; all these are sensible heat transfers. The different cooling loads as discussed in [18], are described as follows:

\subsubsection{Load through the Roof and Walls}

$$
Q=U \times A \times C L T D
$$

where $Q=$ cooling loadthrough roof or wall $(\mathrm{KW} / \mathrm{hr}), U=$ Coefficient of heat transfer in roof, wall or glass $\left(\mathrm{KW} / \mathrm{hr} \cdot \mathrm{m}^{2} \cdot{ }^{\circ} \mathrm{C}\right), A=$ area of roof or walls $\left(\mathrm{m}^{2}\right)$ and $C L T D=$ cooling load temperature difference in ${ }^{\circ} \mathrm{C}[18][19]$.

\subsubsection{Solar Load through Glass}

For solar transmission, the cooling load is calculated using solar heat gain (SHG) and shading coefficient. The cooling load equation for glass is thus expressed in [18] as:

$$
Q=A \times S H G \times S F \times C L F
$$

where $A=$ Area of glass in $\mathrm{m}^{2}, S H G=$ Solar heat gain (which includes effects of both transmission and solar radiation), $S F=$ Shade Factor and $C L F=$ Cooling Load Factor.

\subsection{Internal Cooling Loads}

The various internal loads consist of sensible and latent heat transfers due to occupants, products, process appliances and lighting. Lighting load is only sensible. The conversion of sensible heat gain (from lighting, people, appliances etc.) to space cooling load is affected by the thermal storage characteristics of that space and also subject to appropriate cooling load factors (CLF) to account for the time lag of the cooling load caused by the building mass. The weighting factor equation thus determines the CLF. The internal cooling loads from different sources are expressed [18] [19]:

\subsubsection{People}

$$
\begin{gathered}
Q_{\text {SENSIBLE }}=N \times Q_{S} \times C L F \\
Q_{\text {LATENT }}=N \times Q_{L}
\end{gathered}
$$

where $N=$ number of people in space, $Q_{S}$ and $Q_{L}=$ Sensible and Latent heat gains (obtained from rate of heat gain from occupants of conditioned space), $C L F=$ Cooling Load Factor, by hour of occupancy [18].

\subsubsection{Lights}

$$
Q=3.41 \times W \times F_{U T} \times F_{S A} \times C L F
$$

where $W=$ Watts input from electrical lighting plan or lighting load data, $F_{U T}=$ Lighting use factor(as appropriate), $F_{S A}=$ special ballast allowance factor(as appropriate), $C L F=$ Cooling Load Factor by hour of occupancy [17]. 


\subsubsection{Power Loads}

$$
Q=2545 \times \frac{P}{E f f} \times F_{U M} \times F_{L M}
$$

where $P=$ Horsepower rating from electrical power plants or manufacturer's data, Eff = Equipment motor efficiency (as decimal fraction), $F_{U M}=$ Motor use factor (normally $=1.0$ ), $F_{L M}=$ Motor load factor (normally $=1.0)[18]$.

\subsection{Infiltration Air}

$$
\begin{aligned}
Q_{\mathrm{SENSIBLE}} & =1.10 \times C F M \times\left(T_{o}-T_{i}\right) \\
Q_{\mathrm{SENSIBLE}} & =4840 \times C F M \times\left(W_{o}-W_{i}\right) \\
Q_{\mathrm{TOTAL}} & =4.5 \times C F M \times\left(h_{o}-h_{i}\right)
\end{aligned}
$$

where $C F M=$ infiltration air flow rate, $T_{o}$ and $T_{i}=$ Outside/Inside dry bulb temperature in ${ }^{\circ} \mathrm{C}, W_{o}$ and $W_{i}$ are the Outside/Inside humidity ratio (kg water/ kg dry air), $h_{o}$ and $h_{i}$ are the Outside/Inside air enthalpy (KW/kg dry air) [19].

\subsection{Ventilation Air}

$$
\begin{gathered}
Q_{\mathrm{SENSIBLE}}=1.10 \times C F M \times\left(T_{o}-T_{c}\right) \\
Q_{\mathrm{LATENT}}=4840 \times C F M \times\left(W_{o}-W_{c}\right) \\
Q_{\mathrm{TOTAL}}=4.5 \times C F M \times\left(h_{o}-h_{c}\right)
\end{gathered}
$$

where $C F M$ is the Ventilation airflow rate, $T_{o}=$ Outside dry bulb temperature in ${ }^{\circ} \mathrm{C}, T_{c}=$ Dry bulb temperature of air leaving the cooling coil $\left({ }^{\circ} \mathrm{C}\right), W_{o}=$ Outside humidity ratio in $\mathrm{kg}$ (water) per $\mathrm{kg}$ (dry air), $W_{c}=$ Humidity ratio of air leaving the cooling coil in $\mathrm{lb}$ (water) per $\mathrm{lb}$ (dry air), $h_{o}=$ Outside/Inside air enthalpy in $\mathrm{kW} / \mathrm{kg}$ (dry air), $h_{c}=$ Enthalpy of air leaving the cooling coil in $\mathrm{kW} / \mathrm{kg}$ (dry air) [18].

\section{Results and Discussions}

Building load represents the thermal performance of building structure and its contents. Heat gain or loss through the building envelopes, internal heat loads, ventilation and infiltration are considered in the load calculation to determine the total amount of heat coming in and out of the space in order to maintain the designed indoor thermal comfort conditions. The computed building heating loads were analysed as shown in Tables 1-3. Variations at different orientations were also tabulated. From Tables 1-3, the East/West orientation accounted for $4.87 \%, 3.14 \%$ and $4.74 \%$ increase in cooling capacity for the Faculty of Science, CBN and Chemistry lecture theatres respectively. The fenestration areas at East/West orientation also accounted for increase of 59.75\%, $58.75 \%$ and $58.74 \%$ respectively, for the three lecture theatres being considered. Figures 4-6 show the plotted graph of energy capacity in kilowatts against the sources of cooling load; from the figures, the roof and exposed walls show North/South orientation having more heat gain than the East/West orientation especially for Faculty of Sciences Lecture and Chemistry Lecture theatres.

Table 1. Cooling load estimation for Faculty of Sciences Lecture Theatre.

\begin{tabular}{lcccc}
\hline & *SOCL & $*$ NS $(\mathbf{k W})$ & EW(kW) & Percentage Change \\
\hline $\mathbf{1}$ & Fenestration Areas & 7.05 & 17.08 & 59.75 \\
$\mathbf{2}$ & Roof \& Exposed walls & 26.37 & 23.77 & -10.95 \\
$\mathbf{3}$ & Internal Heat Sources & 43.42 & 43.42 & 0.00 \\
$\mathbf{4}$ & Ventilation \& Infiltration & 78.50 & 79.02 & 0.65 \\
$\mathbf{5}$ & Grand Total Heat & 155.34 & 163.30 & 4.87 \\
\hline
\end{tabular}


Table 2. Cooling load estimation for CBN Lecture Theatre.

\begin{tabular}{rcccc}
\hline & ${ }^{*}$ SOCL & ${ }^{* *} \mathbf{N S}(\mathbf{k W})$ & *** $\mathbf{E W}(\mathbf{k W})$ & Percentage Change \\
\hline $\mathbf{1}$ & Fenestration Areas & 3.58 & 8.67 & 58.75 \\
$\mathbf{2}$ & Roof \& Exposed walls & 42.69 & 44.69 & 4.49 \\
$\mathbf{3}$ & Internal Heat Sources & 63.88 & 63.88 & 0.00 \\
$\mathbf{4}$ & Ventilation \& Infiltration & 114.60 & 114.79 & 0.17 \\
$\mathbf{5}$ & Grand Total Heat & 224.75 & 232.04 & 3.14 \\
\hline
\end{tabular}

Table 3. Cooling load estimation for Chemistry Lecture Theatre.

\begin{tabular}{lcccc}
\hline & *SOCL & ${ }^{* * *} \mathbf{N S}(\mathbf{k W})$ & ${ }^{* * *} \mathbf{E W}(\mathbf{k W})$ & Percentage Change \\
\hline $\mathbf{1}$ & Fenestration Areas & 4.48 & 10.87 & 58.74 \\
$\mathbf{2}$ & Roof \& Exposed walls & 12.51 & 10.04 & -24.64 \\
$\mathbf{3}$ & Internal Heat Sources & 25.45 & 25.45 & 0.00 \\
$\mathbf{4}$ & Ventilation \& Infiltration & 43.90 & 44.28 & 0.86 \\
$\mathbf{5}$ & Grand Total Heat & 86.35 & 90.64 & 4.74 \\
\hline
\end{tabular}

"SOCL: Sources of Cooling Load; ${ }^{* *}$ NS: North/South Orientation; ${ }^{* * *}$ EW: East/West Orientation.

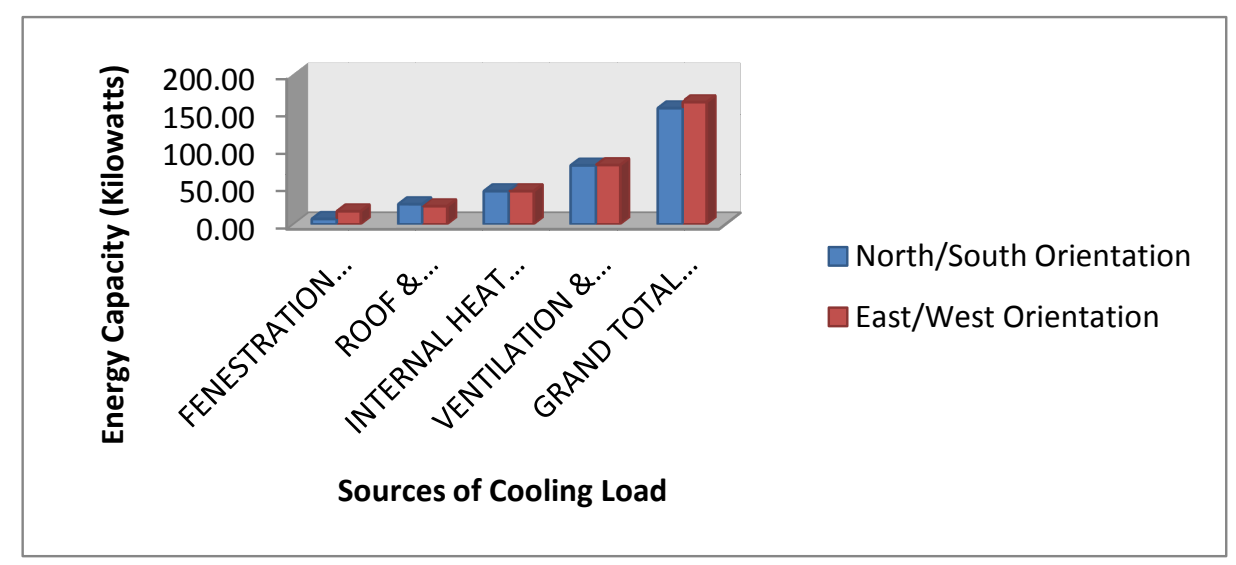

Figure 4. Cooling load estimation for Faculty of Science Lecture Theatre at different orientations.

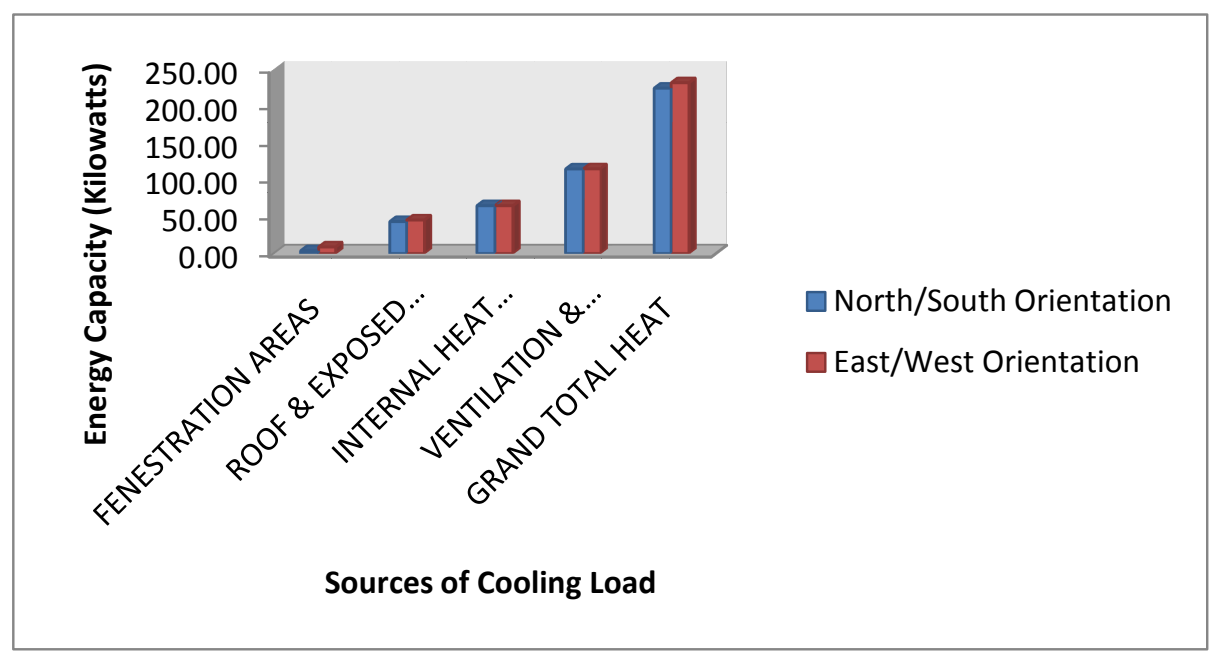

Figure 5. Cooling load estimation for CBN Lecture Theatre at different orientations. 
In addition, Figures 7-9 show the percentage changes in heat gain at both orientations with the cooling load sources in the following order: 1) Fenestration Areas; 2) Roof \& Exposed walls; 3) Internal heat sources; 4) Ventilation \& infiltration and 5) Grand Total Heat for the three lecture theatres considered. The total cooling load estimated for North/South orientation were found to be $155.34,224.75$, and $86.35 \mathrm{~kW}$ while that for East/ West orientation are 163.30, 232.04 and $90.64 \mathrm{~kW}$ for the three lecture theatres respectively. The East/West orientation accounted for an increment in cooling load capacity with 7.96, 7.29 and $4.29 \mathrm{~kW}$ in the Faculty of Science, CBN and Chemistry lecture theatres respectively.

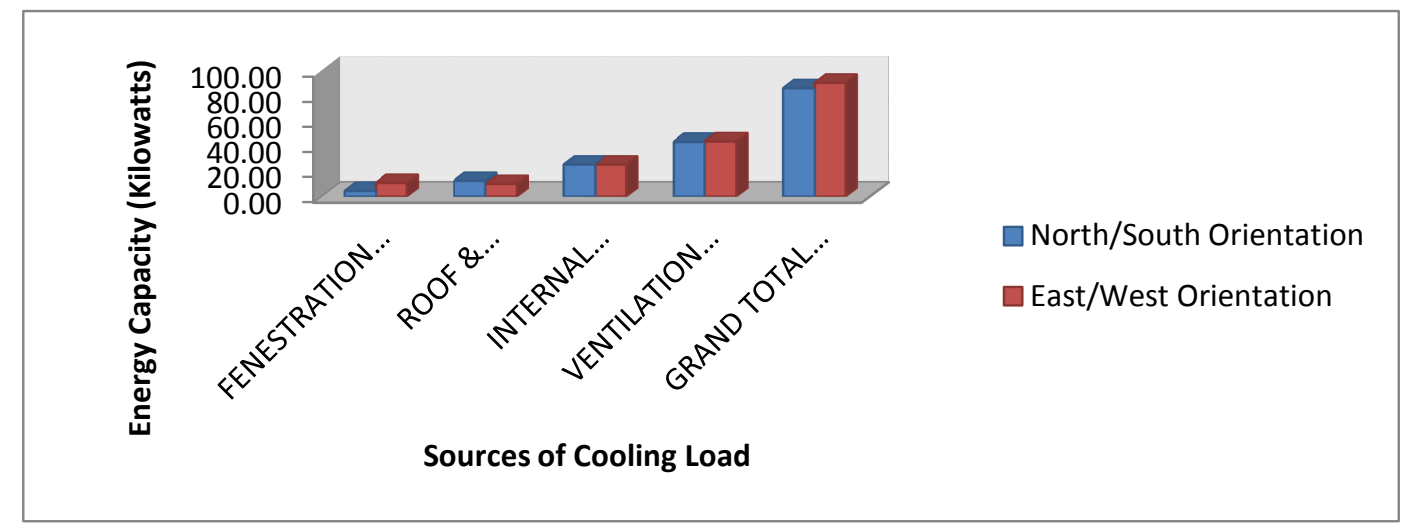

Figure 6. Cooling load estimation for Chemistry Lecture Theatre at different orientations.

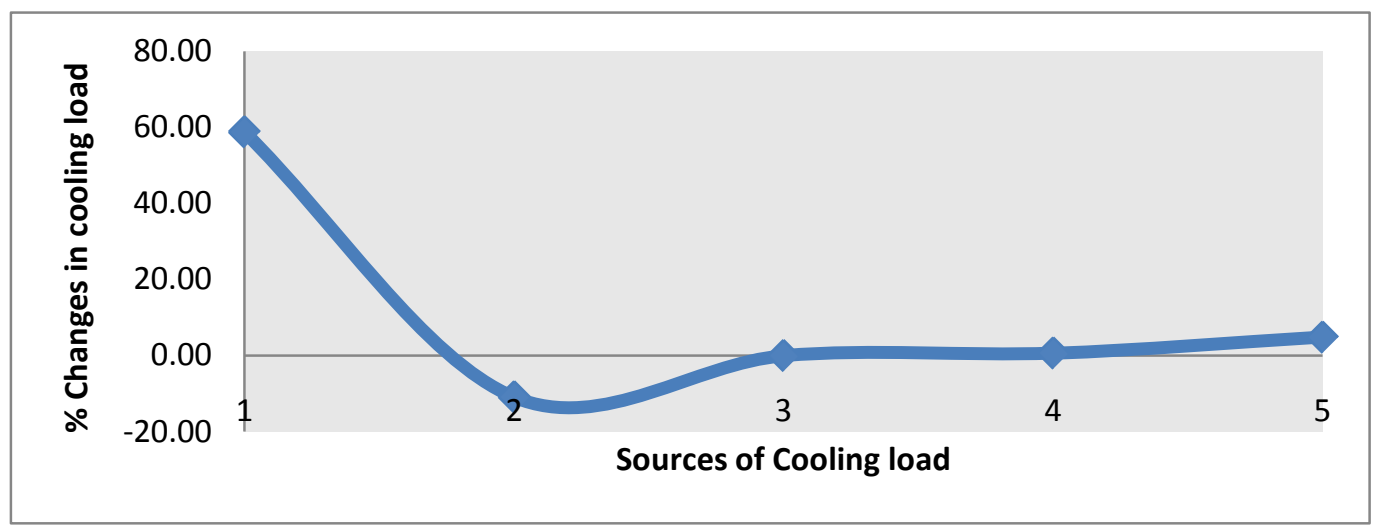

Figure 7. Percentage change in cooling load at different orientation for Faculty of Science Lecture Theatre.

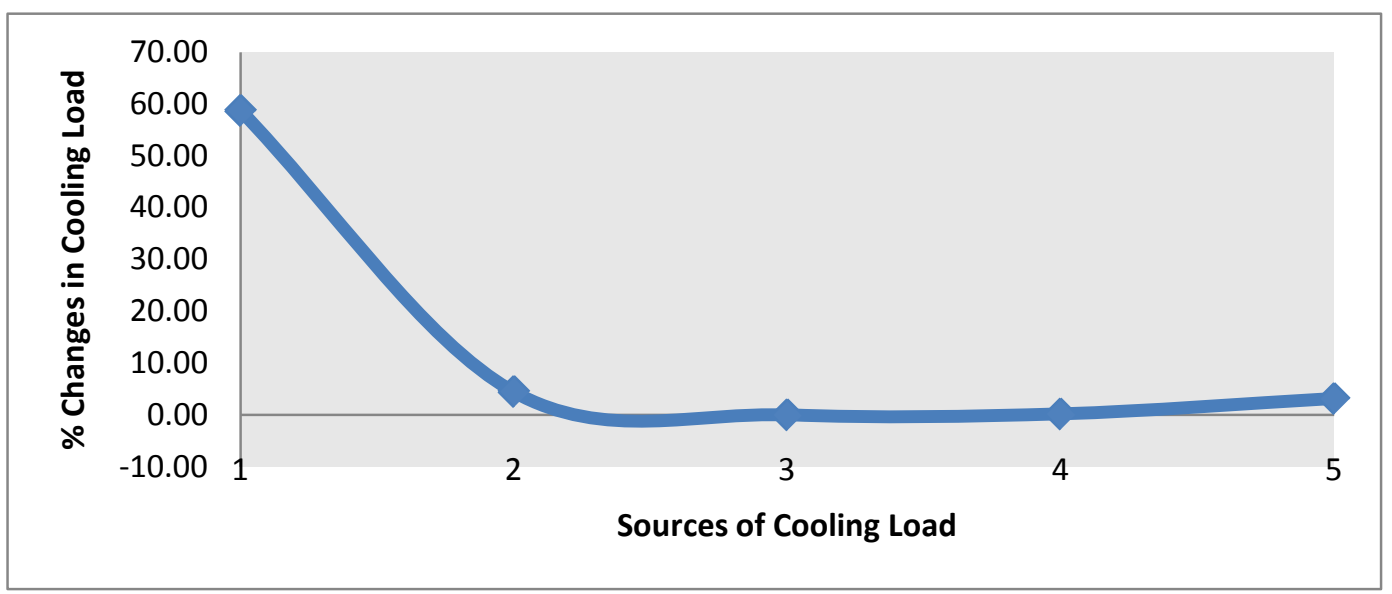

Figure 8. Percentage change in cooling load at different orientation for CBN Lecture Theatre. 


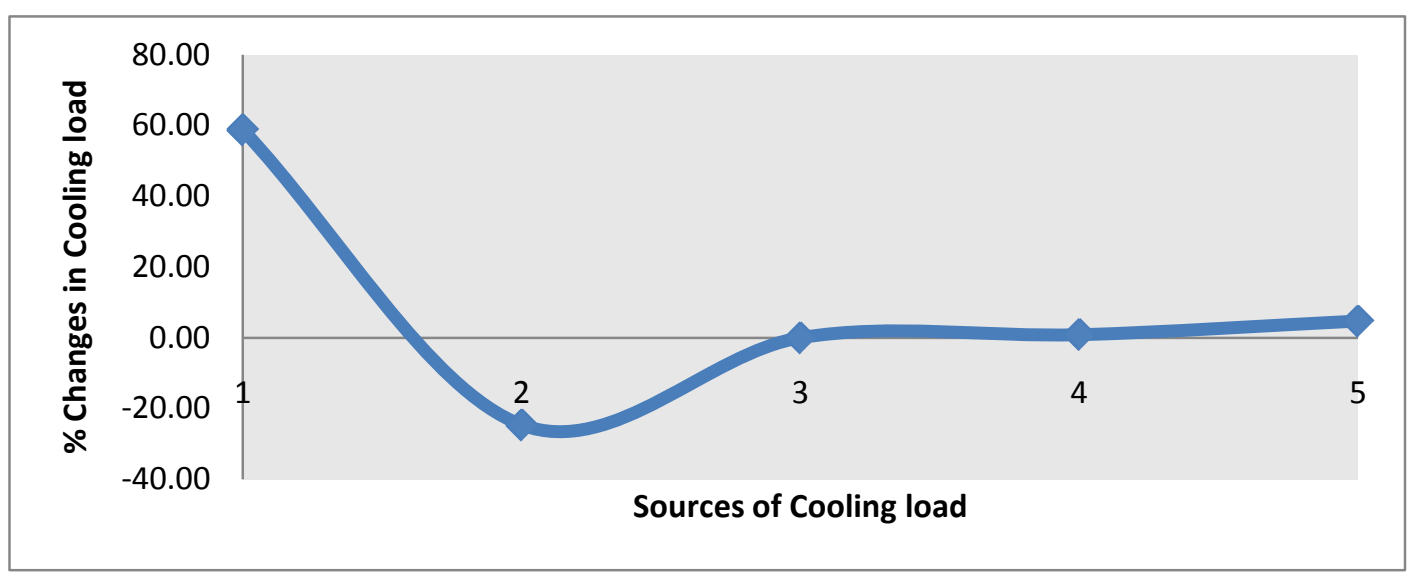

Figure 9. Percentage changes in cooling load at different orientation for Chemistry Lecture Theatre.

\section{Conclusion}

This paper analyzed energy efficiency through different building orientations in three different lecture theatres (Faculty of Science, CBN and Chemistry Lecture Theatres) at the University of Ibadan, Nigeria. The study established North/South building orientation as the best option for the building energy efficiency. This established North/South building orientation also ensure maximum ventilation and natural light in all climatic conditions which invariably provides comfortable living conditions inside the building.

\section{References}

[1] European Council (2002) Energy Performance Building Directive 2002/91/EC of the European Parliament and Council of 16 December 2002 on the Energy Performance in Buildings.

[2] Nicol, F. and Roaf, S. (2005) Post-Occupancy Evaluation and Field Studies of Thermal Comfort. Building Research and Information, 33, 338-346. http://dx.doi.org/10.1080/09613210500161885

[3] Baizhan, L., Runming, Y. and Croome, D. J. (1995) Air Conditioning in China. Buildings Research Information, 23, 309-316. http://dx.doi.org/10.1080/09613219508727483

[4] Yao, R., Li, B. and Steemers, K. (2005) Energy Policy and Standard for Built Environment in China. Renewable Energy, 30, 1973-1988.

[5] Lam, J.C., Wan, K.K.W., Tsang, C.L. and Yang, L. (2008) Building Energy Efficiency in Different Climate. Energy and Building, 01, 013.

[6] Balcomb, J.D. and McFarland, R.D. (1978) Passive Testing in Los Alamos. Los Alamos National Laboratory, Report LA-UR-7B-1178.

[7] Matsuo, Y. (1979) Prediction of Seasonal Load with the Expanded Degree-Day Method. Summaries of Technical Papers of Annual Meetings of AIJ, 39, 837-846.

[8] Christian, J.E. (1983) Thermal Envelope Field Measurements in an Energy-Efficient Office and Dormitory. ORNL/Tm 8571.

[9] Lam, J.C. and Li, D.H.W. (1999) An Analysis of Daylighting and Solar Heat for Cooling-Dominated Office Buildings. Solar Energy, 65, 251-262. http://dx.doi.org/10.1016/S0038-092X(98)00136-4

[10] Cheok, G. (2008) Proposed Legislative Framework on Environmental Sustainability for Buildings.

[11] AL-Najem, A.A. (2002) The Architectural Category and Its Importance to Measure the Electrical Energy Demand and to Identify Effective Conservation Measures. The 1st Symposium on Energy Conservation and Management in Buildings Conference, SAK, (I), 99-110.

[12] La Roche, P. and Liggett, R. (2001) A Web Based Assistant for the Design of Climate Responsive Buildings. Architectural Science Review, 44, 437-448. http://dx.doi.org/10.1080/00038628.2001.9696924

[13] Wagner, A., Gossauera, E., Moosmanna, C., Groppa, T. and Leonhart, R. (2007) Thermal Comfort and Workplace Occupant Satisfaction: Results of Field Studies in German Low Energy Office Buildings. Energy and Buildings, 39, 758-769. http://dx.doi.org/10.1016/i.enbuild.2007.02.013

[14] Bala, E.J., Ojosu, J.O. and Umar, I.H. (2000) Government Policies and Programmes on the Development of Solar PV 
Sub-Sector in Nigeria. Nigeria Journal of Renewable Energy, 8, 1-6.

[15] Ohunakin, O.S., Adaramola, M.S., Oyewola, O.M. and Fagbenle, R.O. (2014) Solar Energy Applications and Development in Nigeria: Drivers and Barriers. Renewable and Sustainable Energy Reviews, 32, 294-301. http://dx.doi.org/10.1016/j.rser.2014.01.014

[16] Ojo, O. (2000) Fundamentals of Physical and Dynamic Climatology. SEDEC Publication, Lagos.

[17] American Society of Heating, Refrigerating and Air-Conditioning Engineers (ASHRAE) (2009) Fundamental Handbook. ASHRAE, Atlanta.

[18] American Society of Heating, Refrigerating and Air-Conditioning Engineers (ASHRAE) (1997) Fundamental Handbook. ASHRAE, Atlanta.

[19] American Society of Heating, Refrigerating and Air-Conditioning Engineers (ASHRAE) (1985) Fundamental Handbook. ASHRAE, Atlanta. 